\section{NSF Notes}

\section{Program Supports U.S.-U.S.S.R. Cooperation in Basic Research}

An NSF program for U.S.-U.S.S.R. Cooperation in the Field of Basic Scientific Research seeks to contribute to the advancement of scientific knowledge through the support of long-term cooperative research projects between U.S. and Soviet scientists and scientific institutions. The program is designed to complement other opportunities for cooperation between U.S. and Soviet scientists.

Only proposals in areas and topics of basic scientific research mutually agreed to by the NSF and the Soviet Academy of Sciences are eligible for support. General topical areas include mathematics, theoretical physics, scientific problems of the Arctic and the North, geosciences, chemistry, life sciences, and engineering sciences. Specific topics are listed in the program announcement available from NSF at the address below.

All proposals must be based on direct cooperation between U.S. and Soviet scientists who wish to work together in a project of common scientific interest. Plans for all joint activities are to be developed directly between the U.S. and Soviet principal investigators, who submit their proposals in parallel to the NSF and the U.S.S.R. Academy of Sciences. Proposals will be evaluated independently by U.S. and Soviet sides and will require joint approval.

Each side must share in the cost and effort of each project. Although a precise matching of funds, personnel, facilities, or time spent in each country by scientists of the other is not required, each project should result in the achievement of substantial mutual benefit.

The program is intended to cover incremental costs incurred directly as a result of the international collaboration, primarily the transportation and subsistence of participants, expendable materials and supplies, publication charges, etc. Proposals may be linked to ongoing or proposed sources of funding for domestic "core research" support.

Telephone consultation or submission of informal preliminary proposals to NSF prior to formal proposal submission is strongly encouraged.

For additional information and deadlines, contact the U.S.-U.S.S.R. Cooperative Research Program, Room 1212, Division of International Programs, National Science Foundation, Washington, DC 20550; telephone (202) 3577494; fax (202) 357-5839.

\section{Proposals Invited for SGER Program}

The National Science Foundation is inviting SGER proposals for small-scale, exploratory, high-risk research in all fields of science, engineering and education normally supported by NSF. Such research is characterized as:

- Preliminary work on untested and novel ideas;

- Ventures into emerging research areas;

- Application of new expertise and new approaches to "old" research topics;

- Multidisciplinary work, particularly crossing NSF program boundaries;

- Research having a severe urgency with regard to availability or access to data, facilities, or specialized equipment; or

- Efforts of similar character likely to catalyze rapid and innovative advances.

Award amounts will vary by program and are expected to be substantially less than a given program's average amount. No SGER award will exceed $\$ 50,000$. The nonrenewable awards are normally made for one year and will not exceed two years. More than one investigator may be supported on one SGER award, and investigators without prior NSF support are encouraged to apply.

Proposers are strongly encouraged to contact the appropriate NSF program officer before submitting a proposal to determine if the proposed work meets SGER guidelines, if funding is likely to be available, or if the idea should be considered for submission as a fully reviewed proposal.

Information about specific NSF programs and contacts is generally available from institutional sponsored research offices or in the following publications: Grants for Research and Education in Science and Engineering (NSF 83-57, Revised); the NSF Guide to Programs; and the monthly NSF Bulletin. Single copies of any of these publications are available by writing to the Forms and Publications Unit, Room 232, NSF, Washington, DC 20550.

For details about SGER proposals contact the National Science Foundation, 1800 G Street, Washington, DC 20550; telephone (202) 357-9859.

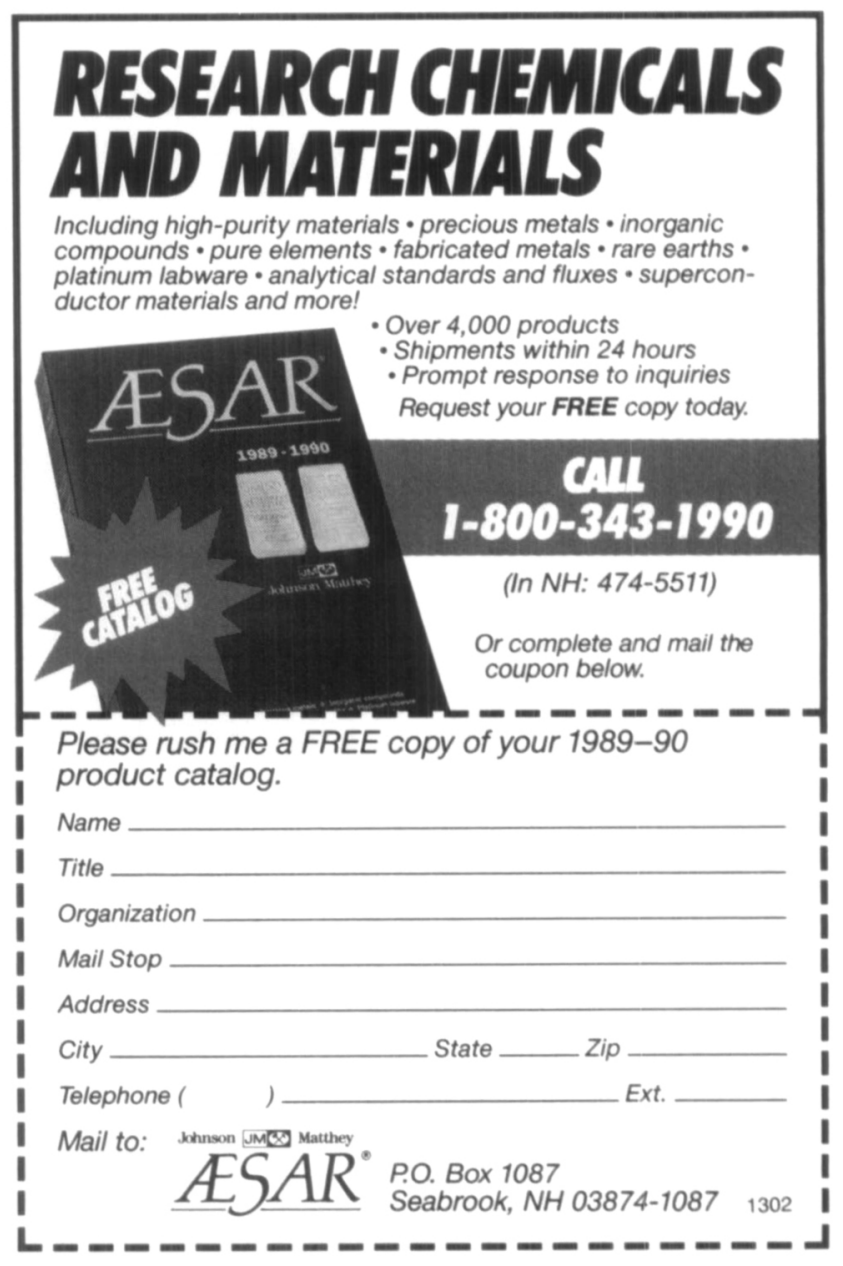

